\title{
Pendampingan Revitalisasi Lapangan Desa Ngabeyan Kecamatan Kartasura Kabupaten Sukoharjo
}

\author{
Suryo Handoyo ${ }^{1}$, Teguh Yuono ${ }^{2}$ \\ Universitas Tunas Pembangunan Surakarta ${ }^{1,2}$ \\ e-mail: suryo.handoyo@lecture.utp.ac.id ${ }^{1}$, teguh.yuono@ lecture.utp.ac.id ${ }^{2}$
}

\begin{abstract}
Abstrak
Desa Ngabeyan adalah desa di wilayah Kecamatan Kartasura, Sukoharjo, Jawa Tengah. Kartasura adalah kecamatan yang mempunyai lokasi strategis sebagai titip pertemuan jalur mobilisasi barang dan manusia. Jalur Jogya, Semarang dan Solo sebagian besar akan melewati wilayah Kartasura. Potensi wilayah sebagai titik pertemuan jalur adalah timbulnya potensi strategis wilayah tersebut. Pertambahan kepadatan hunian dan semakin rapatnya mobilisasi barang dan manusia. Kondisi tersebut akan membawa konsekuensi yang bersifat positif dan negatif yang harus mulai diantisipasi guna kehidupan masyarakat yang lebih baik. Desa Ngabeyan memiliki lapangan Ngabeyan yang merupakan aset sangat potensial karena keberadaan tanah terbuka yang cukup luas di tengah wilayah yang semakin rapat adalah sesuatu yang bernilai. Perlu ada optimalisasi potensi tersebut sehingga dapat lebih memberi kemanfaatan. Guna mencapai hal tersebut maka tim pengabdian masyarakat akan melakukan desain lapangan Ngabeyan. Dengan tujuan agar keberadaan lapangan tersebut dapat lebih bermanfaat dan mudah dalam perawatan.
\end{abstract}

Kata kunci: revitalisasi, desain lapangan, kemanfaatan, operasional perawatan

\begin{abstract}
Ngabeyan Village is a village in the District of Kartasura, Sukoharjo, Central Java. Kartasura is a district that has a strategic location as a meeting point for the mobilization of goods and people. The Jogya, Semarang and Solo lines will mostly pass through the Kartasura area. Regional potential as a point of meeting lane is the emergence of the strategic potential of the region. Increased occupancy density and increasingly tight mobilization of goods and people. These conditions will bring positive and negative consequences that must begin to be anticipated for a better community life. Ngabeyan village has a Ngabeyan field which is a very potential asset because the existence of a large enough open land in the middle of an increasingly dense area is something of value. There needs to be optimization of this potential so that it can further benefit. To achieve this, the community service team will design the Ngabeyan field. With the aim of the existence of the field can be more useful and easy to maintain.
\end{abstract}

Keywords: revitalization, field design, expediency, maintenance operations

\section{PENDAHULUAN}

Desa Ngabeyan mempunyai luas wilayah $118 \mathrm{Ha}$ dengan lahan sawah $49 \mathrm{Ha}$. Batas utara desa tersebut berbatasan dengan desa Klegen, Colomadu Karanganyar. Wilayah selatan berbatasan dengan kelurahan Kartasura. Wilayah Timur berbatasan dengan desa Singapuran. Untuk Wilayah Barat berbatasan dengan desa Wiragunan. Wilayah Ngabeyan termasuk dalam kecamatan Kartasura, kabupaten Sukoharjo, Jawa Tengah. Secara astronomi lapangan ngabeyan terletak $7^{\circ} 32^{\prime} 50.09^{\prime \prime}$ bujur selatan dan $110^{\circ} 44^{\prime} 31.13^{\prime \prime}$. Wilayah tersebut memiliki posisi yang strategis karena berada di titik pertemuan jalur Semarang, Yogya dan Solo. Kondisi tersebut membawa efek pertambahan penduduk secara cepat sehingga meningkatkan mobilisasi manusia dan barang. Suatu wilayah yang pertumbuhan infrastruktur tidak terencana dapat menyebabkan tidak optimalnya proses kegiatan sosial dan ekonomi daerah tersebut. Perlu adanya pendampingan dalam proses perencanaan salah satu komponen infratruktur guna mulai meminimalisir kegagalan pertumbuhan infrastruktur 


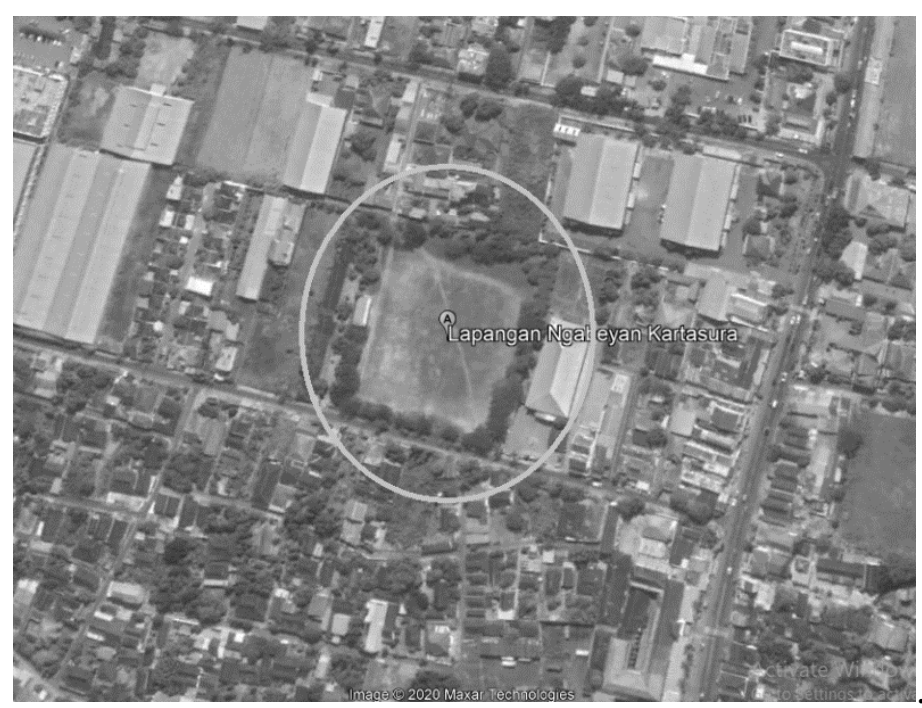

Gambar 1. Lokasi Lapangan Desa Masaran (Sumber: Citra Satelit Google Maps, 2020)

Desa Ngabeyan memiliki potensi lapangan bola. Pada kondisi sekarang ini lapangan tersebut kurang terawat dikarenakan kendala secara umum di manajemen dan secara khusus pada biaya perawatan. Team pengabdian masyarakat berusaha melakukan diskusi dengan perangkat guna memperoleh data terkait kondisi dan harapan pengelolaan lapangan tersebut. Ada beberapa point informasi yang diperoleh, bahwa perangkat desa Ngabeyan menyadari potensi yang mereka miliki. Lapangan desa Ngabeyan tersebut dapat digunakan untuk kegiatan sosial kemasyarakatan yang sesuai dengan budaya sekitar.

Adapun tujuan dilakukan pengabdian kepada masyarakat untuk kegiatan Revitalisasi Lapangan Desa Ngabeyan Kecamatan Kartasura Kabupaten Sukoharjo yaitu dapat mengurai serta memberikan solusi terbaik dari problem yang terjadi di lapangan sedangkan untuk manfaatnya agar keberadaan lapangan tersebut dapat lebih bermanfaat dan mudah dalam perawatan.

\section{METODE}

Pelaksanaan pengabdian kepada masyarakat dilaksanakan dengan 2 tahapan yaitu tahapan persiapan dan pelaksanaan. Tahap persiapan dilakukan untuk melakukan diskusi dengan perangkat desa Ngabeyan tentang rencana pelaksanaan pengabdian masyarakat oleh tim Dosen. Dari diskusi tersebut diharapkan akan diperoleh informasi secara benar. Diskusi tersebut juga berguna untuk menentukan langkah berikutnya demi terwujudnya kondisi yang diharapkan. Juga mulai direncanakan langkah aplikasi pengambilan data di lapangan berikut koordinasi dengan perangkat desa terkait otoritas wilayah berada di perangkat desa Ngabeyan. Posisi tim pengabdian masyarakat Dosen hanya sebagai konsultan yang tidak mempunyai kewenangan memutuskan. Otoritas tim pengabdian masyarakat Dosen hanya memberikan saran dan usulan yang bersifat membangun dalam koridor rasional dan terukur. Tahapan pelaksanaan dilakukan melalui serangkaian kegiatan yang akan antara lain : a) Melakukan kompilasi data pengukuran, dokumentasi foto, dan lain-lain sebagai bahan untuk proses analisis, b) Melakukan analisis tapak terhadap kondisi tapak lokasi lapangan Ngabeyan, c) Melakukan pemetaan lapangan desa Ngabeyan, d) Melakukan analisis ruang yang sesuai dengan kebutuhan, e) Membuat gambar pra-desain berupa gambar site-plan, denah dan perspektif, f) Dari bahan pra-desain yang telah disusun, dilakukan diskusi dengan semua tim dan calon pengguna untuk mendapatkan masukan dan saran untuk perbaikan pra-desain, g) Setelah mendapat persetujuan gambar pra-desain maka dibuat perhitungan struktur gambar detailnya untuk gambar pelaksanaan 
konstruksi, h) Penyusunan gambar detail untuk pelaksanaan konstruksi, i) Penyusunan analisa yang diperlukan sebagai pendukung, j) Penyusunan perkiraan rencana anggaran biayanya (RAB). Peran aktif mitra antara lain diskusi dalam perencanaan revitalisasi lapangan desa Ngabeyan dan menjadi pelaksana dalam revitalisasi lapangan Ngabeyan.

\section{HASIL DAN PEMBAHASAN}

Hasil yang dapat dihimpun untuk kegiatan pengabdian ini dibagi menjadi 3 topik yaitu survei pendahuluan, pelaksanaan pendampingan revitalisasi, dan penyusunan analisa rencana anggaran biaya.

Survei pendahuluan merupakan kegiatan untuk mendapatkan informasi dan data awal yang diperlukan di lokasi pengabdian yang nantinya akan berguna untuk analisis lebih lanjut. Survei pendahuluan untuk pengabdian ini harus melalui beberapa tahapan seperti tahap perijinan, survei lokasi, dan diskusi awal.
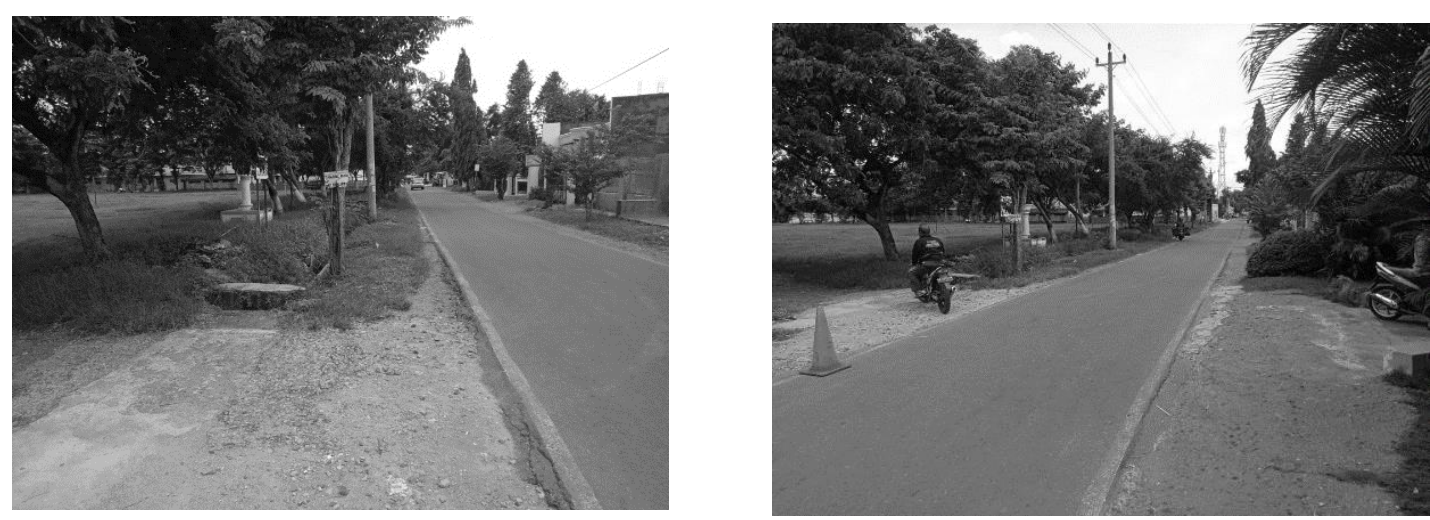

Gambar 2. Akses Jalan Sekitar Lapangan
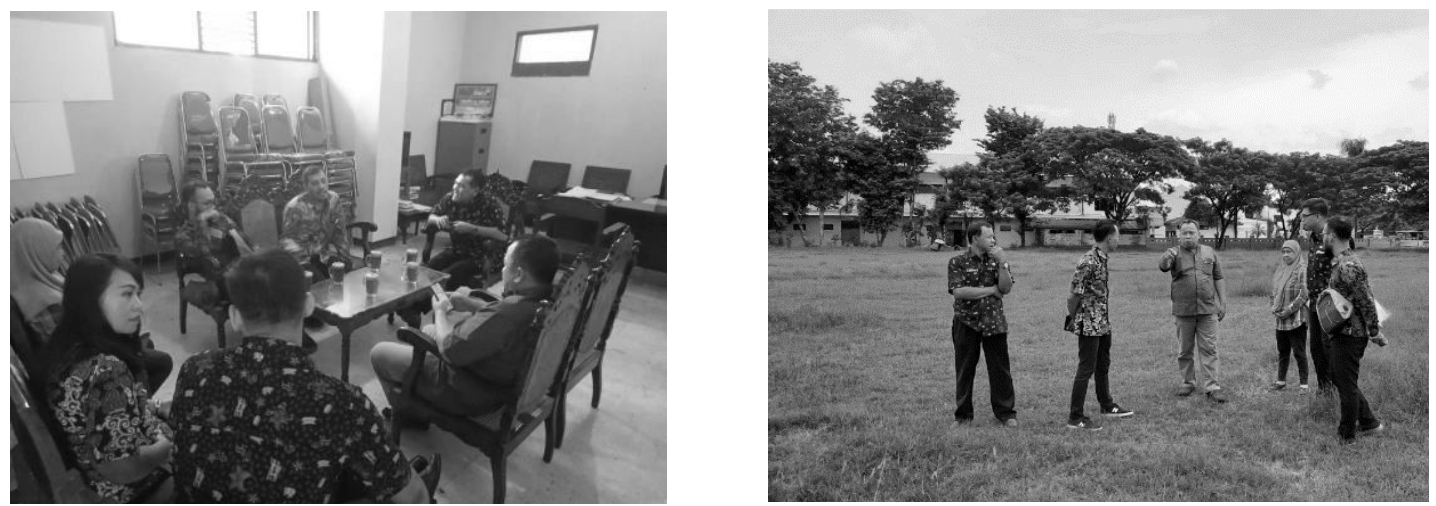

Gambar 3. Diskusi dengan perangkat desa

Pada tahap perijinan, tim pengabdian akan memberikan surat tugas terlebih dahulu ke perangkat desa terkait. Kemudian dilakukan kegiatan survei lokasi. Adapun permasalahan yang ditemukan ketika survei lokasi yaitu diantaranya pembersihan lapangan yang tidak dilakukan secara teratur (a) kerbersihan lapangan, (b) renovasi tribun upacara dan relokasi tiang bendera, (c) penataan 
lapangan dengan menambahkan fasilitas olahraga, (d) Perbaikan saluran. Adapun gambaran permasalahan tersebut dapat dilihat seperti berikut.

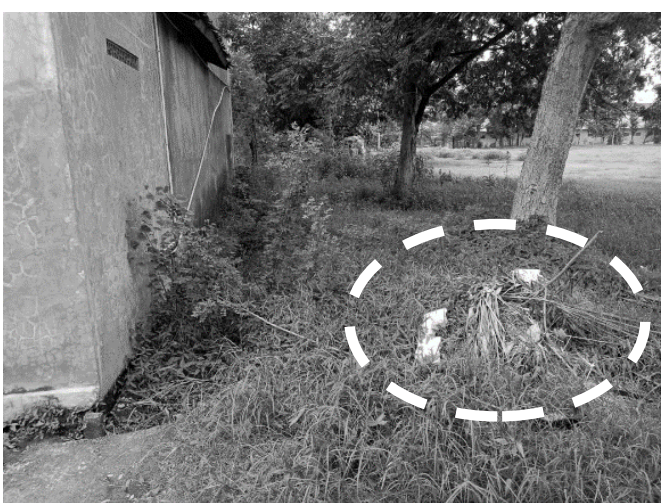

(a)

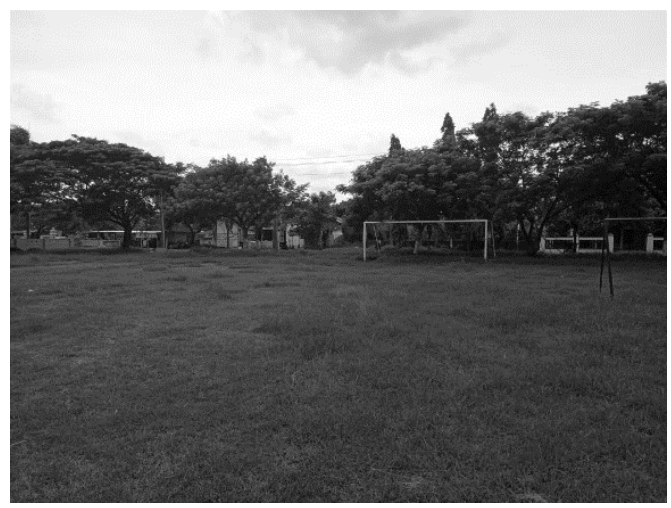

(c)

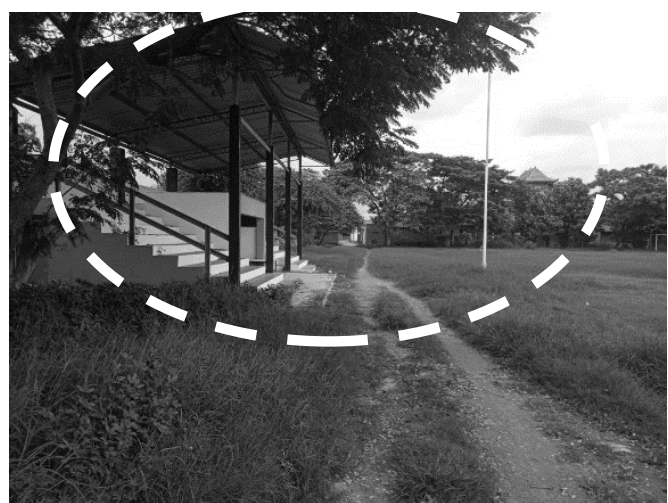

(b)

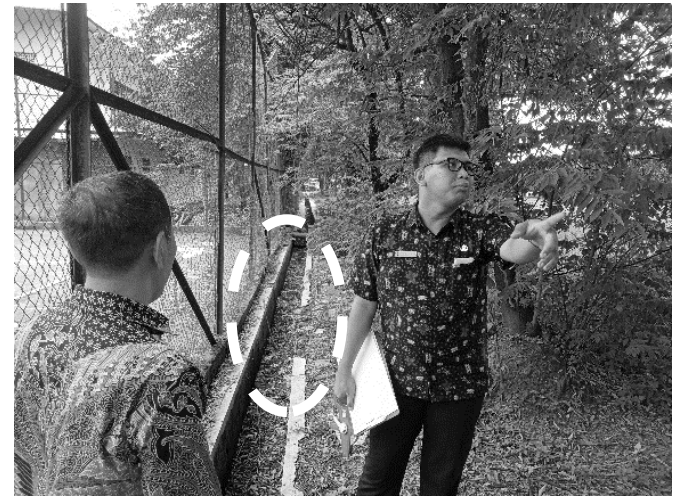

(d)

Gambar 4. Permasalahan di Lapangan
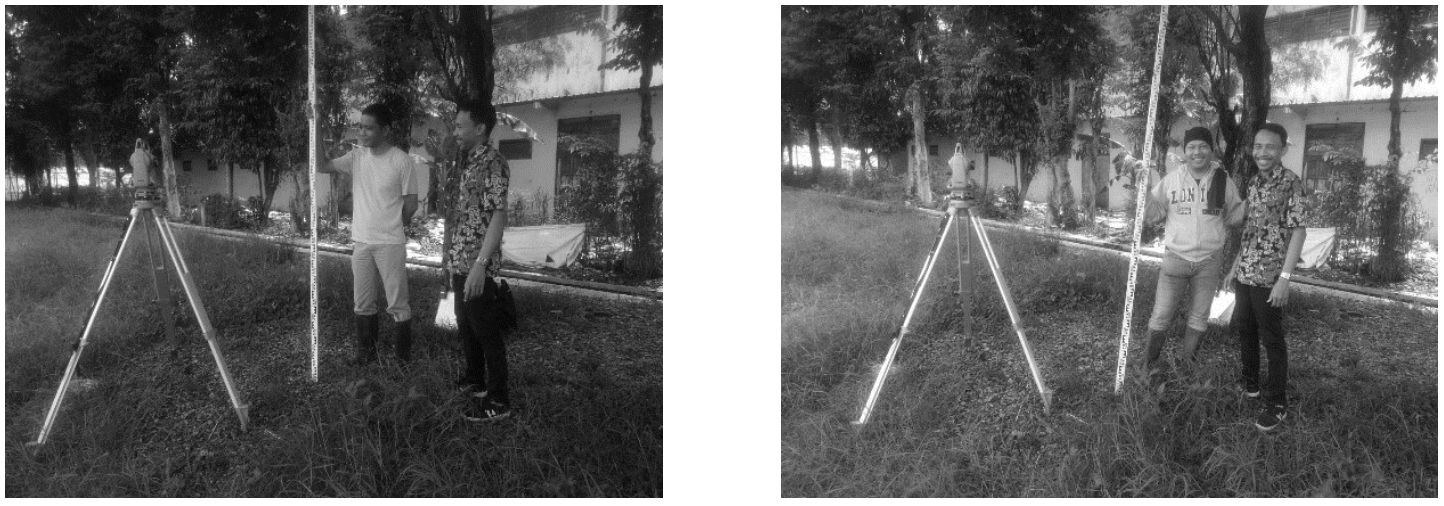

Gambar 5. Survey Topografi

Berdasarkan permasalahan tersebut diatas akan direncanakan item pekerjaan yang sesuai untuk menyelesaikan permasalahan tersebut. Adapun item pekerjaan yang menjadi pokok dalam kegiatan ini diantaranya pekerjaan saluran drainase di tepi lapangan, pekerjaan jogging track, pekerjaan lapangan sepak bola , pekerjaan lapangan bola basket, pekerjaan blok area senam, bermain anak, dan sekitarnya, pekerjaan blok area UKM parkir dan entrance, pekerjaan gedung pengelola, mushola, dan KM/WC. Untuk lebih jelasnya dapat dilihat seperti gambar berikut. 


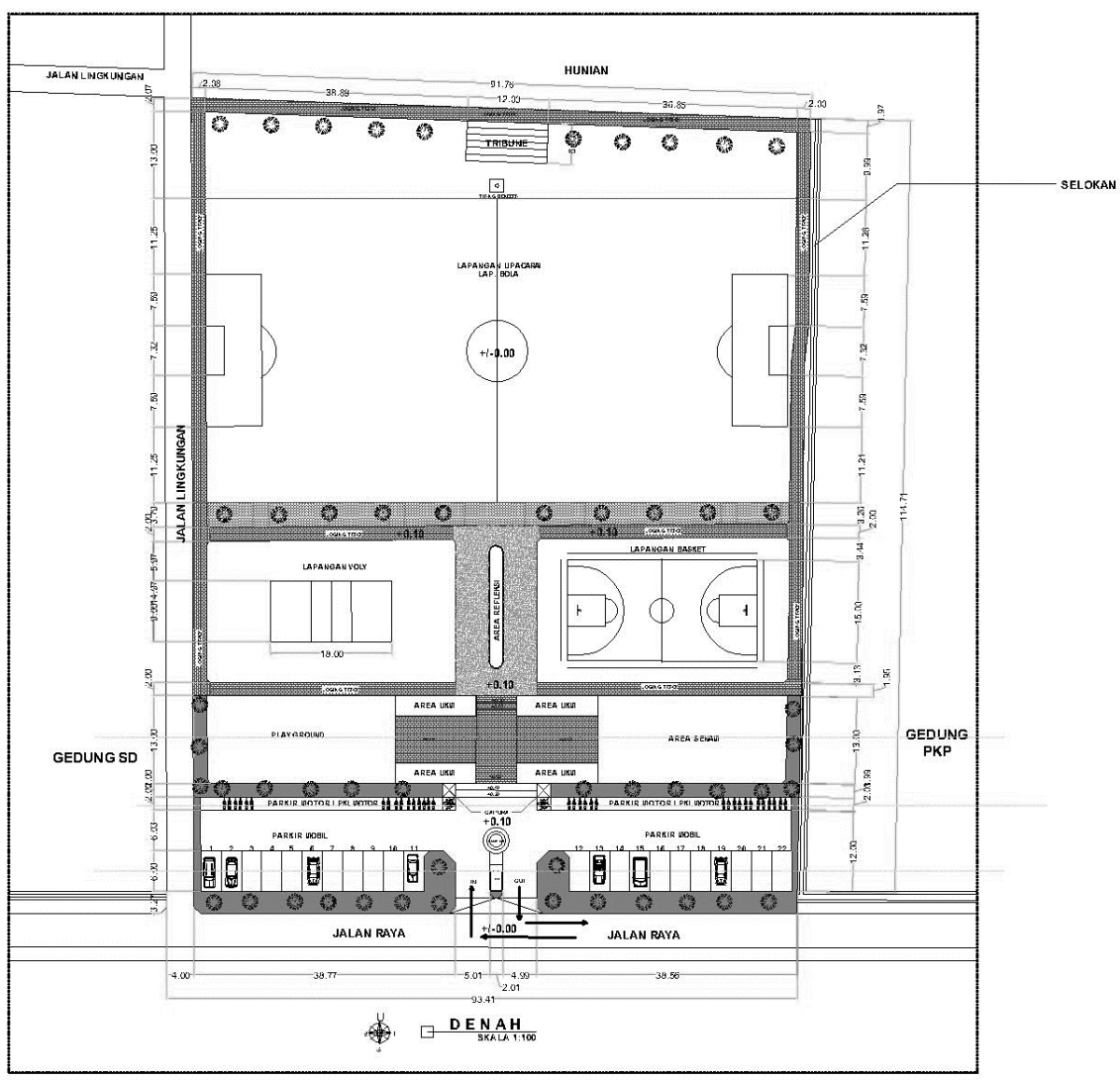

Gambar 6. Denah Revitalisasi Lapangan Ngabeyan

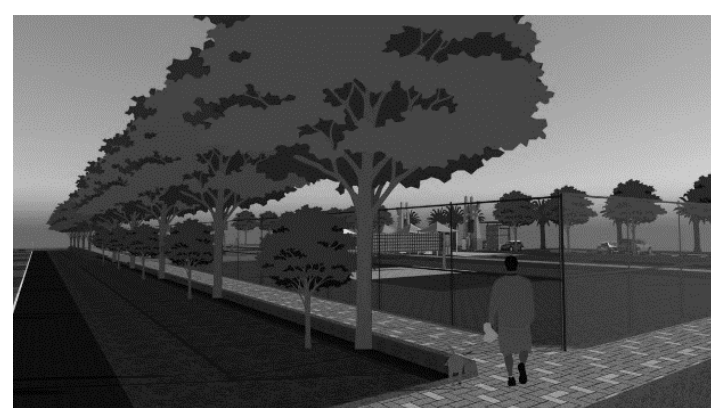

(a)

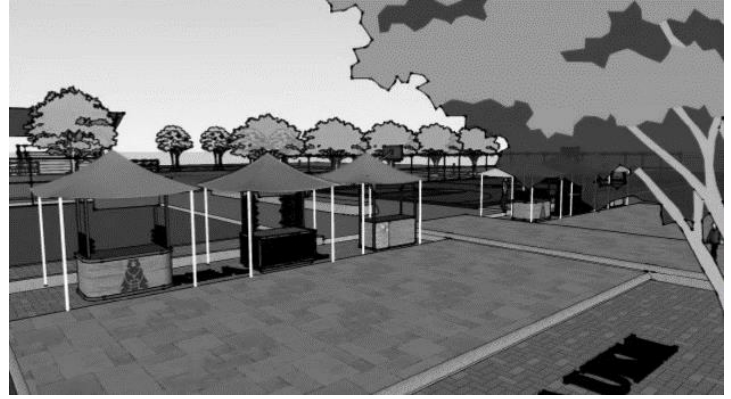

(b)

Gambar 7. Area Penonton (a) dan Sentra UKM (b)

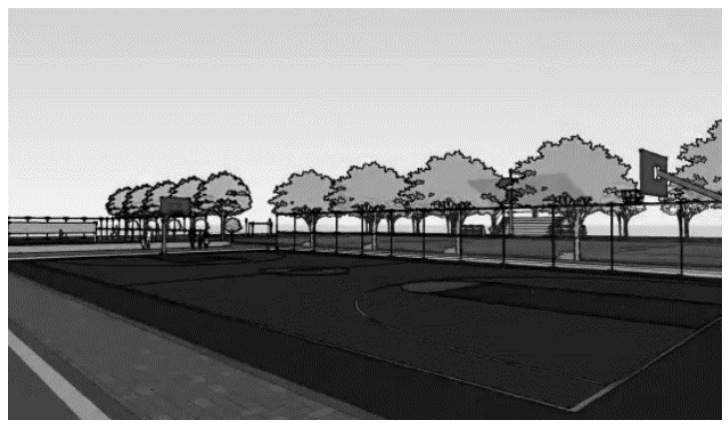

(a)

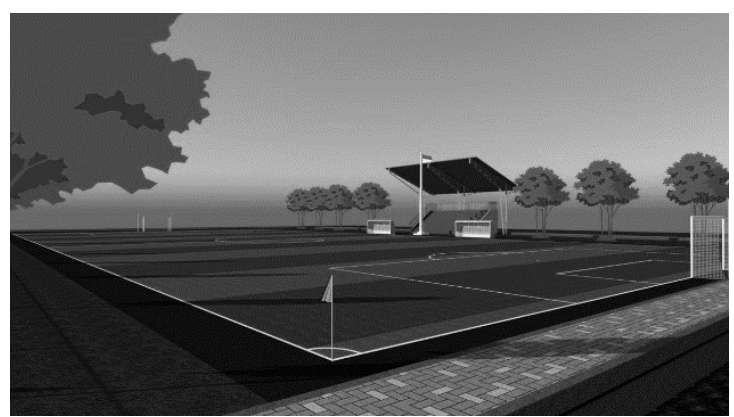

(b)

Gambar 8. Lapangan basket (a) dan Lapangan Sepak (b) 


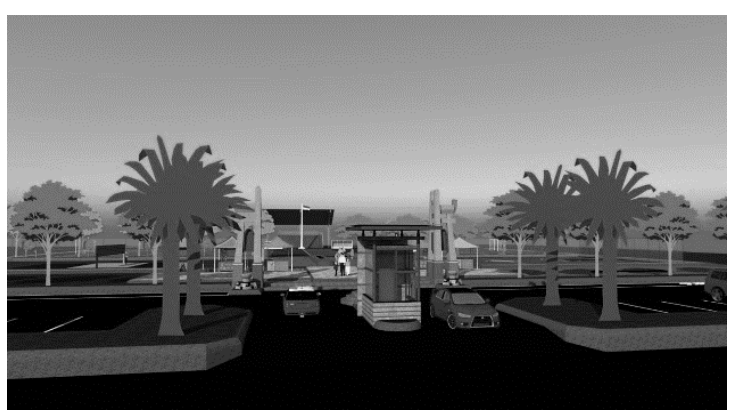

(a)

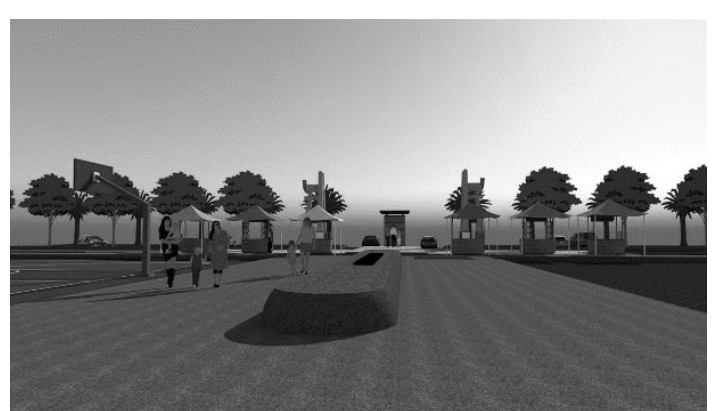

(b)

Gambar 9. Pos jaga (a) dan Area pejalan kaki (b)

Pada perencanaan kali ini untuk anggaran biaya kami tekankan pada perbaikan drainase terlebih dahulu, karena merupakan sarana yang vital untuk mendukung bangunan-bangunan yang akan direncanakan. Adapun anggaran biaya untuk perbaikan saluran adalah sebagai berikut:

Tabel 1. Rekapitulasi Rencana Anggaran Biaya perbaikan saluran

\begin{tabular}{clr}
\hline NO & \multicolumn{1}{c}{ URAIAN PEKERJAAN } & JUMLAH \\
\hline 1. & PEKERJAAN SALURAN DRAINASE TEPI LAPANGAN & \\
\hline a. & PEKERJAAN PERSIAPAN & \\
b. & PEKERJAAN SALURAN PASANGAN BATU KALI BAGIAN TIMUR & $\mathbf{7 1 , 6 8 7 , 1 9 2}$ \\
c. & PEKERJAAN SALURAN PASANGAN BATU KALI BAGIAN UTARA & $53,674,944$ \\
d. & PEKERJAAN SALURAN PASANGAN BATU KALI BAGIAN BARAT & $\mathbf{7 1 , 6 8 7 , 1 9 2}$ \\
\hline GRAND TOTAL & $\mathbf{2 0 5 , 2 2 6 , \mathbf { 1 5 8 }}$ \\
\hline PEMBULATAN & $\mathbf{2 0 5 , 2 0 0 , 0 0 0}$ \\
\hline
\end{tabular}

\section{SIMPULAN}

Tim pengabdian kepada masyarakat telah melaksanakan pendampingan dalam melakukan perencanaan revitalisasi lapangan Desa Ngabeyan Kecamatan Kartasura Kabupaten Sukoharjo. Untuk kegiatan tahap pertama yaitu perbaikan drainase lapangan Ngabeyan ini dapat diketahui besarnya anggaran biaya adalah sebesar Rp. 205.200.000,00.

\section{UCAPAN TERIMA KASIH}

Penulis mengucapkan terima kasih kepada Universitas Tunas Pembangunan yang telah memberi dukungan dana dalam pelaksanaan pengabdian ini.

\section{DAFTAR REFERENSI}

Abidin, H.Z. 2007, Penentuan Posisi dengan GPS dan Aplikasinya, Pradnya Paramita Jakarta.

Badan Pertanahan Nasional. 1998. Petunjuk Teknis Peraturan Menteri Negara Agraria/Kepala Badan Pertanahan Nasional no 3 Tahun 1997 Materi Pengukuran dan Pemetaan Pendaftaran Tanah. Badan Pertanahan Nasional Republik Indonesia.

Badan Pusat Statistik. 2019. Kabupaten Sragen dalam Angka. Badan Pusat Statistik.

Badan Pusat Statistik. 2019. Kecamatan Masaran dalam Angka. Badan Pusat Statistik. 
Das, Braja M. 1998. Mekanika Tanah (Prinsip-prinsip Rekayasa Geoteknis) jilid 1, Erlangga, Jakarta.

Mukomuko, Ir.J.A. 1985. Dasar Penyusunan Anggaran Biaya Bangunan. Jakarta, Gaya Media Pratama.

Rochmanhadi, 1990, Pengantar dan Dasar-dasar Pemindahan Tanah Mekanis. Jakarta: Yayasan Badan Penerbit Pekerjaan Umum.

Rochmanhadi, 1993, Perhitungan Biaya Pelaksanaan Pekerjaan dengan Menggunakan Alat-alat Berat. Cetakan ke-2 Jakarta: Yayasan Badan Penerbit Pekerjaan Umum.

Suripin, 2003, Sistem Drainase Perkotaan yang Berkelanjutan, Yogyakarta, Andi 